Denis Bouchard, ancien professeur de l'Université de Toronto, poète et artiste, offre souvent ses créations spirituelles et ludiques à LittéRéalité.

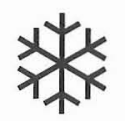

\title{
Toronto flirt
}

G rand dortoir

le plus vaste du monde

où même les pelouses sont fécondes tant il y a de jolis petits chiens.

Image de lubricité contenue, l'hôtel de ville, un rien pornographique, restera pourtant chaste - vu le flip-flop de la Tour $C N$, avec son flirt de seringue - : incompatibilité bétonnée. 


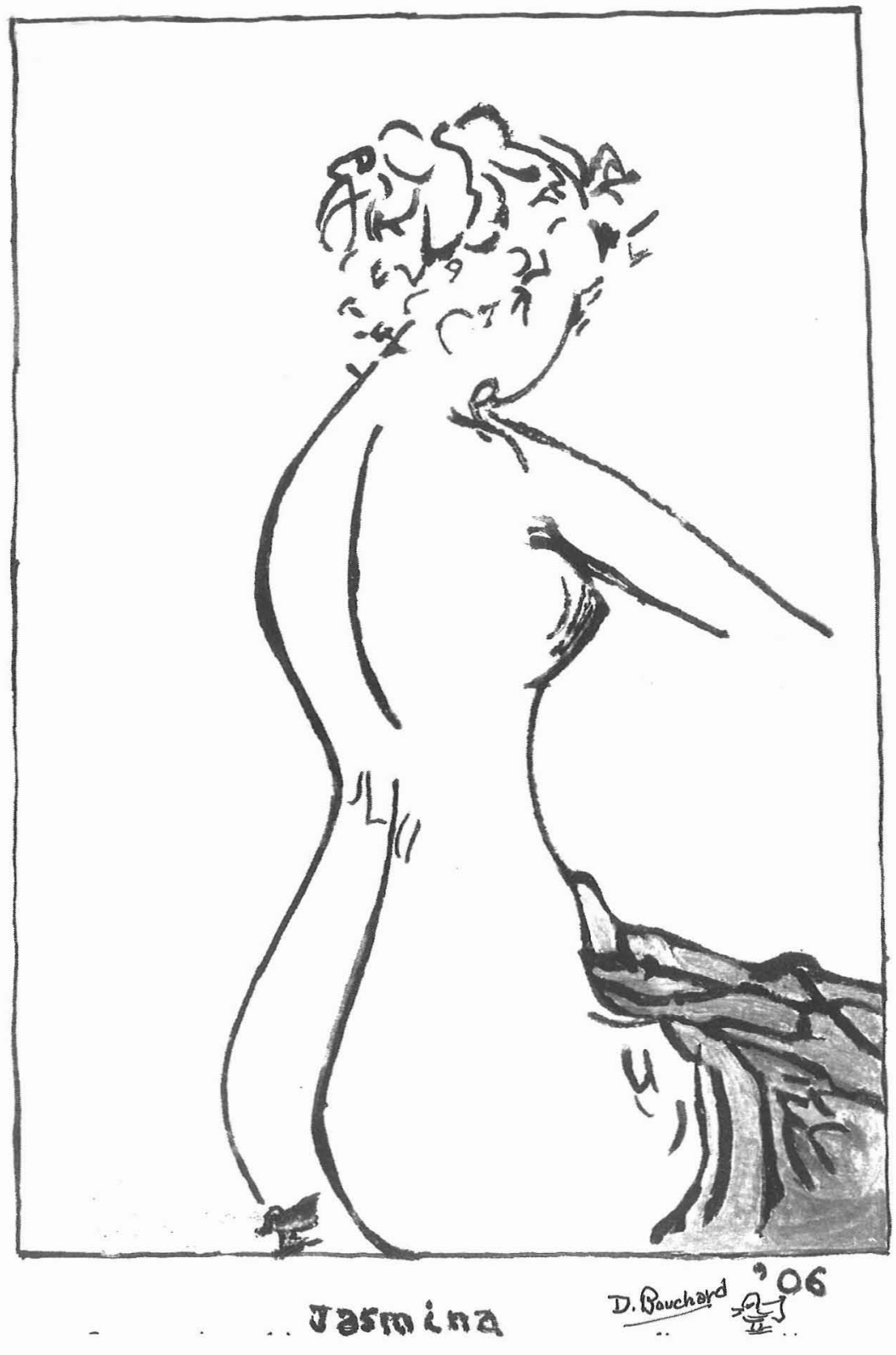

Denis Bouchard

Jasmina 


\section{慗}

La complainte du Violon pas cher

Ce fut pour la farouche $\mathrm{K}$

une autre histoire d'apaisement.

Trois violons au choix proposés,

pour qu'elle rentre au foyer.

"Je ne jouerai jamais

sur ce violon minable!"

À son retour, un tchèque pas cher

l'attendait! Les autres rendus,

avant son arrivée; sournois

les parents visés se cabrèrent :

"Je ne jouerai jamais

sur ce violon minable!"

Cinq ans plus tard, soir de grand froid, larme à l'œil — de joie cette fois un chouette instrument français ramena le bien-être au cour :

" J'ai retrouvé mon compagnon

de rêve - adieu coup de fil manqué!? 